\title{
AOR
}

Selected Papers of \#AoIR2020:

The $21_{\text {st }}$ Annual Conference of the Association of Internet Researchers Virtual Event / 27-31 October 2020

\section{A GOOD LIFE? CRITICAL FEMINIST APPROACHES TO INFLUENCER ECOLOGIES}

Arturo Arriagada

Universidad Adolfo Ibáñez

Sarah Banet-Weiser

London School of Economics and Political Science

Sophie Bishop

Kings College London

Brooke Erin Duffy

Cornell University

Joanne Entwistle

Kings College London

Zoë Glatt

London School of Economics and Political Science

Agnès Rocamora

London College of Fashion

Francesca Sobande

Cardiff University

Elizabeth Wissinger

The City University of New York

Suggested Citation (APA): Arriagada, A., Banet-Weiser, S., Bishop, S., Duffy, B. E., Entwistle, J., Glatt, Z., Rocamora, A., Sobande, F. \& Wissinger, B. (2020, October). A good life? Critical feminist approaches to influencer ecologies. Panel presented at AolR 2020: The 21th Annual Conference of the Association of Internet Researchers. Virtual Event: AolR. Retrieved from http://spir.aoir.org. 


\section{Panel overview}

Social media platforms are widely lauded as bastions for entrepreneurial selfactualisation and creative autonomy, offering an answer to historically exclusive and hierarchical creative industries as routes to employability and success. Crystal Abidin defines influencers as "everyday, ordinary Internet users who accumulate a relatively large following on blogs and social media through the textual and visual narration of their personal lives and lifestyles" $(2016$, p.3). In 2020, influencer content can lie on a spectrum of amateur to highly professional; mythologies about influencers' independence have also been complicated as we catch glimpses of managers, photographers and PR teams. Social media influencers are envied by audiences as having achieved 'the good life', one in which they are able to 'do what they love' for a living (Duffy 2017). This is augmented by the supposed 'authenticity' of self-presentation as it also hinges on personal disclosure, capturing domestic life and 'backstage' moments. Despite this ostensive accessibility and relatability, today's high-profile influencer culture continues to be shaped by 'preexisting gendered and racial scripts and their attendant grammars of exclusion' as Sarah Banet-Weiser (2012) argued in the early days of socially mediated entrepreneurship (p. 89; see also Bishop, 2017). In Western contexts only a narrow subset of white, cis-gender, and heterosexual YouTubers, Instagrammers, TikTokers, and Twitch streamers tend to achieve visibility as social media star-creators, and celebratory discourses of diversity and fairness mask problematic structures that exclude marginalized identities from opportunities to attain success.

Perhaps not surprisingly, the lack of diversity among the digital creator community fails to register in popular culture, shrouded as it is by cheering assertions about Internetenabled diversity and the well-worn promise of meritocracy. A key aim of this panel is thus to draw attention to marginalized creator communities and subjectivities, including women, non-white, and queer creators, all of whom face higher barriers to entry and success. The panelists, moreover, draw attention to new systems of inequality emerging at the interface of technology and creative industry, including platform algorithms and technological tools that purport to scout out "brand friendly content", that exacerbate other forms of inequality that have deep roots in the media and cultural industries (Gill, 2013).

More broadly, by taking seriously both the practices and discourses of social media influencers, the panellists aim to challenge popular denigrations of influencers as vapid, frivolous, or eager to freeload. We locate such critiques in longstanding dismissals of feminized cultural production (Levine, 2013) and argue, instead, that we need to take seriously the role of influencers in various social, economic, and political configurations. In this manner, we capture more about the various ways users try to wield the power of these platforms, however lopsided these attempts may be. These collected analyses reveal the complexity of financial co-optation, where users are both rewarded and punished for taking risks, speaking out, and being 'real' for their followers, according to a capricious calculus whose contours are opaque to many. Consequently, these papers draw out moments of political and social intent however muddied they become as they engage with the economic imperatives of platforms. This panel offers new research that 
makes significant interventions into the ongoing conversation about influencer ecologies. To that end, this interdisciplinary panel utilises critical feminist methods that emphasize diverse forms of value and meaning-making, to explore the culture of influencers within the wider contexts of marketing, education, politics, and family life. We reject claims examining influencer cultures is niche; as life is increasingly lived contingent to social media platforms, influencer cultures offer glimpses into how our identities and outputs will become increasingly commodified.

\section{References}

Abidin, C. (2016). "Aren't these just young, rich women doing vain things online?": Influencer selfies as subversive frivolity. Social Media+ Society, 2(2), 2056305116641342.

Banet-Weiser, S. (2012). Authentic ${ }^{\mathrm{TM}}$ : The politics of ambivalence in a brand culture. New York, NY: NYU Press.

Bishop, S. (2017). Beauty for Girls, Pranks for Boys-It's the Same Old Gender Stereotypes for YouTube Stars'. The Conversation, 4.

Gill, R. (2013). Inequalities in media work. In Behind the Screen (pp. 189-205). Palgrave Macmillan, New York.

Duffy, B. E. (2017). (Not) getting paid to do what you love: gender, social media, and aspirational work. New Haven: Yale University Press.

Levine, E. (Ed.). (2015). Cupcakes, pinterest, and ladyporn: Feminized popular culture in the early twenty-first century. University of Illinois Press. 


\title{
ALGORITHMIC INFLUENCER MANAGEMENT TOOLS: A FEMINIST CRITIQUE OF PEG AND THE EYE
}

\author{
Sophie Bishop \\ Kings College London

\section{Introduction}

This paper explores two proprietary algorithmic influencer management tools designed to support marketers in selecting influencers for marketing campaigns. Influencers are categorised and ranked according to subjective judgements of 'brand safety'. Tools deepen surveillance of influencer content by advertising stakeholders, who hope to predict and manage the likelihood of influencer 'scandals', and to hegemonize influencer behaviour more broadly. For example, L'Oreals Chief Digital Officer, Cedric Dordain, told The Drum 'we want more detail about the background of the influencers. From what they've posted in the past - not just on Instagram but on any social platform and any website or blog or forum'. The risk-management software sold within influencer marketing industries is in line with often discriminatory risk-management software used across sectors, such as HR (Gray \& Suri, 2019) or healthcare (Eubanks, 2017). Both software levy historic data from influencer profiles and campaigns to support automated decision-making processes. Firstly I consider Peg, a UK-based influencer marketing tool enabling stakeholders to identify brand-safe influencers. Secondly, The Eye is a custom application designed by 'marketing services and media company' StyleHaul using their proprietary data to "help brands see who the best influencers for their campaign'. StyleHaul ceased operations in 2019, and it is unclear what became of The Eye (launched in 2017). The tool remains a valuable case study, however, as its operations are comparable with competitors such as Traakr, Upfluence, and Mavrck. This paper seeks to provide a theoretical and conceptual framework for understanding how brand safety is predicted and measured using digital tools in marketing industries. This framework synthesises feminist critiques of ostensibly participatory influencer industries (Abidin, 2016; Duffy, 2017; Oh \& Oh, 2017) with close attention to critical algorithmic studies (Bucher, 2018; Cheney-Lippold, 2017; Gillespie, 2017). I demonstrate how value-laded algorithmic judgements map onto well-worn hierarchies of desirability and employability, originating from systemic and historic bias along the lines of class, race and gender.

\section{Methodology}

Often the fetishization of the complexity of algorithms is a 'red herring, a piece of information that distracts from the other' (Bucher, 2018: 44). There are no guarantees that cracking open the black box will reveal secrets or make the roots of bias or discrimination visible in algorithmic systems. There is methodological opportunity in studying the ancillary content that surrounds algorithms and their formations; including 'press releases, conference papers on machine learning techniques... media reports, blog posts' in addition to other texts and resources (Bucher, 2018: 61). 
Thus, my methodology involved gathering background information about Peg and StyleHaul including White Papers, About Us pages, marketing and press guidance, podcasts, trade press coverage and conference presentations. I negotiated access to Peg for one month, and used the 'walkthrough method', combining STS and cultural studies approaches to systematically analyse Peg's 'technological mechanisms and embedded cultural references' (Light, Burgess, \& Duguay, 2018: 882). I walked-through the Peg platform as a brand, interrogating its features, options and guidelines. Data gathered was coded for information about the tools and their expected use (for brands, influencers, management), representations of algorithmic processes and information about categorisation, predictions and ranking cultures. Despite the clear limitations of being unable to reveal how algorithmic tools work, the patchwork approach employed in this paper can demonstrate how such tools are conceived, sold and embedded within marketing industries and promotional cultures.

\section{Findings}

I concentrate on three primary findings: I consider how discrimination manifests within both Peg's brand safety and audience consistency scores, and in StyleHaul's measurement of influencer face shape. Taken together, these examples illustrate how bias becomes baked into software, and how this impacts influencers' employment opportunities and broad visibility.

Peg gives each influencer a 'brand safety' score, measuring instances of profanity in an influencers' video metadata (titles, tags) and spoken words in video content using language processing. It is clear that Peg's algorithms cannot measure context or attend to sustained and intricate intersections of raced, class and gendered identity within social life. For example, the word 'queer' is coded as profanity, lowering brand safety scores. This categorisation speaks to a longstanding sexualisation of queer people, in addition to the more recent examples of the demonetization of LGBTQ+ content on YouTube. Similarly $n^{*}$ gger is coded as a naughty word, a decision that shows how minority groups can be penalised for reclaiming words that have historically been used against them.

Peg measures a like/dislike ratio, designed to anticipate creator scandals. In practice, it measures an audience's tolerance for creator behaviours. For example, gaming vlogger Pewdiepie's use of anti-Semitic language has been widely profiled, yet he has high audience consistency score of 9/10. Indeed, influencers whose brands are built on being controversial tend to have very consistent like/dislike ratios, a positive metric for their overall Safety Score. This score is not measuring how offensive or unjust an influencers' content is in context. Rather, measuring dislikes from a creators' own audience is a proxy for measuring that audience's tolerance of such content. Backlash is uneven. It is important to recognise that women and people of colour are more vulnerable to trolling attacks that diminish an Audience Consistency score and overall Safety Score, both used by brands make recruitment decisions.

Finally, for The Eye the 'the shape of a creator's face impacts post performance more than any other facial characteristic measured'. Although StyleHaul do not outline their 
methodology for measuring face shape (or other characteristics) they show a positive correlation between facial characteristics and beauty campaign success. In one test 'heart shaped faces performed best'. Through social media content, influencers' face shapes are algorithmically processed and categorised. In this vein, The Eye reveals an underlying influencer 'aesthetic economy', showing the value of the right look (Entwistle, 2002). The Eye's categorisations reveal how raced definitioms of beauty underpin participation in influencer industries. Mythologies of creativity and democracy, that 'anyone can be a fashion blogger' have informed the development and professionalisation of influencer industries (Duffy, 2017: 4). Although the promise of creative participation is intoxicating, algorithmic tools used by gatekeepers can revealing the practical barriers for those hoping to make it as influencers, and creative labourers more broadly in the UK and beyond.

\section{References}

Abidin, C. (2016). "Aren't These Just Young, Rich Women Doing Vain Things Online?": Influencer Selfies as Subversive Frivolity. Social Media+ Society, 2(2),

Bucher, T. (2018). If...then: Algorithmic power and politics. Oxford University Press.

Cheney-Lippold, J. (2017). We Are Data: Algorithms and The Making of Our Digital Selves. New York University Press.

Duffy, B. E. (2017). (Not) Getting Paid to Do What You Love: Gender, Social Media, and Aspirational work. Yale University Press.

Entwistle, J. (2002). The aesthetic economy: The production of value in the field of fashion modelling. Journal of Consumer Culture, 2(3), 317-339.

Eubanks, V. (2017). Automating inequality: How high-tech tools profile, police, and punish the poor (First Edition). St. Martin's Press.

Gillespie, T. (2017). Algorithmically recognizable: Santorum's Google problem, and Google's Santorum problem. Information, Communication \& Society, 20(1),

Gray, M. L., \& Suri, S. (2019). Ghost work: How to stop Silicon Valley from building a new global underclass.

Oh, D. C., \& Oh, C. (2017). Vlogging White Privilege Abroad: Eat Your Kimchi 's Eating and Spitting Out of the Korean Other on YouTube: Vlogging White Privilege Abroad. Communication, Culture \& Critique, 10(4), 696-711. 


\title{
BEYOND THE BLACK/WHITE BINARY: “INTERRACIAL” VLOGGER CULTURE AND PROSPECTIVE “MIXED” MICROMICROINFLUENCERS
}

\author{
Francesca Sobande \\ Cardiff University
}

\section{Introduction}

Contemporary marketplace contexts are inherently shaped by structural racism and colonial legacies which propel the commodification of people, places and cultures (Johnson et al., 2019). As it exists within a broader consumer culture which is steeped in intersecting inequalities and oppression, influencer culture is always a site and source of power struggles that reflect and reveal socio-political hierarchies entangled with capitalism. Therefore, influencer culture-from viral TikTok trends to the vlogs of YouTubers-are mediated by a market logic that, I argue, is tethered to what hooks (1992) refers to as white supremacist capitalist patriarchy. Approached from this perspective, in this paper I analyze the content of vloggers whose self-brands stem from their (re)presentations of being in an 'interracial' relationship. This analysis addresses how whiteness functions in the construction of 'interracial' couple vlogger brands, in ways linked to issues concerning gender, sexuality and parenthood. More specifically, I study what depictions of the offspring of such vloggers and their parenting of their children suggest about the racial dynamics of vlogger culture-especially the appeal of 'micromicroinfluencers' (Abidin, 2015; 2017).

\section{Methodology}

Using critical technocultural discourse analysis (CTDA), which is a 'multimodal analytic technique for the investigation of Internet and digital phenomena, artifacts, and culture' (Brock, 2018: 1012), I interpretively analyze the content of 20 high-profile 'interracial' couple vloggers—such as Jamie and Nikki, The Rush Fam, AdannaDavid, SliceNRice and KKandbabyJ. CTDA 'decenters the Western deficit perspective on minority technology use to instead prioritize the epistemological standpoint of underrepresented groups of technology users' (Brock, 2020: 2). Thus, such a holistic analytic approach which involves treating 'technology as discourse, practice, and artifact' (ibid.) is attuned to the agentic, strategic and creative ways that racialized people use digital media and technology-including as vloggers.

Drawing on critical race and digital studies (Benjamin, 2019; Noble and Tynes, 2016; Noble, 2018), Black cyberfeminism (Gray, 2015), Abidin's (2018) research on internet celebrity, and the work of Burgess and Green (2009) on YouTube, I analyze the vlog content of 'interracial' couples that involve a Black and a white spouse, the vlog content of 'interracial' couples that do not involve white people, as well as online comments accompanying all of these vlogs. Tacking back and forth between the content of the vloggers under review and the online comments that they yield, I examine the explicit and implicit ways that issues regarding race and racism are made manifest in this digital environment. Overall, I explore how depictions of, allusions to, and the visual absence of white people and structural whiteness operate in the context of these vlogs, the 
branding of 'interracial' couple vloggers, the online discourse that surrounds them, and, by extension, consumer culture in general.

\section{Findings}

Eschewing dualistic binaries of Blackness and whiteness, I study how a range of racial identities, as well as related experiences of coupledom, parenthood and childhood, are portrayed in the content of 'interracial' couple vloggers and the digital discourse that they are located within. In doing so, I account for how gender norms and heteronormative ideals play out in these vlogs in ways inextricably linked to race and a market logic underpinned by demand for palatable depictions of so-called 'diversity'. I explicate the potential marketability of such couples' 'mixed-race' and often lightskinned children, including what connected vlog activity illustrates in relation to the (inter)racial dynamics of vlogger culture and 'micromicrocelebrity' (Abidin, 2015). My paper accounts for the omnipresent nature of a structurally white gaze in many facets of influencer culture, by considering how some 'interracial' couple vloggers leverage their proximity to whiteness and gear their content towards a so-called 'postracial' audience - in ways that are demonstrative of white supremacist capitalist patriarchy. This work offers a contribution to studies of vlogger and influencer culture by articulating and unpacking often unacknowledged racial dynamics, and elucidating how aspects of 'micromicrocelebrity; (Abidin, 2015) are moulded by a market appeal associated with racial 'mixedness'.

\section{References}

Abidin, C. (2015). 'Microcelebrity: Branding babies on the Internet' M/C Journal 18(5). Retrieved from http://journal.media-culture.org.au/index.php/mcjournal/article/view/1022

Abidin, C. (2017). '\#familygoals: Family influencers, calibrated amateurism, and justifying young digital labor'. Social Media + Society, 3(2), 1-15.

Abidin, C. (2018). Internet Celebrity: Understanding Fame Online. Bingley: Emerald.

Benjamin, R. (2019). Race After Technology: Abolitionist Tools for the New Jim Code. Cambridge: Polity Press.

Brock, A. (2018) 'Critical technocultural discourse analysis'. New Media \& Society, 20(3), 1012-1030.

Brock, A. (2020) Distributed Blackness: African American Cybercultures. New York: New York University.

Burgess, J. and Green, J. (2009). YouTube: Online Video and Participatory Culture. Cambridge: Polity Press. 
Gray, Kishonna L. (2015). 'Race, gender, and virtual inequality: Exploring the liberatory potential of Black cyberfeminist theory.' In Rebecca Lind (ed.) Produsing Theory in a Digital World 2.0: The Intersection of Audiences and Production in Contemporary Theory, pp. 175-190. New York: Peter Lang.

hooks, bell. (1996). Reel to Real: Race, Sex and a Class at the Movies. New York: Routledge.

Johnson, G.D., Thomas, K.D., Harrison, A.K. and Grier, S.A. (2019). Race in the Marketplace: Crossing Critical Boundaries. Cham: Palgrave Macmillan.

Noble, S.U. and Tynes, B.M. (eds.) (2016). The Intersectional Internet: Race, Sex, Class, and Culture Online. New York: Peter Lang.

Noble, S.U. (2018). Algorithms of Oppression: How Search Engines Reinforce Racism. New York: New York University Press. 


\title{
'YOU DON'T DRESS LIKE A MUM!' INSTAGRAM 'STYLE MUMS' CHALLENGING THE FASHIONABLE IDEAL
}

\author{
Joanne Entwistle \\ Kings College London \\ Elizabeth Wissinger \\ The City University of New York
}

This paper examines Instagram style mums in the UK and moms in the US (for the sake of stylistic brevity, we refer to our sample as 'mums' throughout) and how they articulate their desire to be identified both as a mum and 'fashionable' self. Outside the fashion elite's control, how do these style mums perform fashion/style and what space is opened up for alternatives to the fashionable ideal? These mums' 'authenticity' challenges the 'homogenizing logic' (Findlay et al., 2019: 24) of the fashion image, displaying a more inclusive fashionable aesthetic on Instagram. With a critical awareness of the limits of the platform, our visual and textual analysis revealed clear attempts to carve out new spaces in fashion for 'mums' amidst latent forces pulling for marketable behaviors.

\section{Context}

The social media literature has yet to examine the Instagram style mum. Work on 'mumpreneurs' (Ekinsmyth, 2013; 2014; Eikhof, 2013; Orgad, 2019) tends to treat fashion as a background issue. The Media and Communication analyses have noted the presence of mums on Instagram, but their primary focus is young women using these platforms for entrepreneurial gain as 'lifestyle influencers' and 'microcelebrities' (Abidin, 2016; Marwick, 2013; Senft, 2008) within the rise of 'Instafame' (Marwick, 2013) and 'entrepreneurial self-branding' (Duffy and Hund, 2015) and 'aspirational labor' (Duffy 2017). Fashion Studies' exclusive focus on celebrity 'influencers' has not surprisingly found Instagram colonised by big brands and aesthetics very similar to mainstream fashion (Findlay et al., 2019).

\section{Methodology}

For our analysis, we chose 'ordinary' Instagrammers who identify as 'mum,' and pair it with 'style' or 'fashion,' i.e., model outfits and display their bodies on a regular basis, to see how their displays potentially challenge the fashionable ideal. Searching mama style, mum or mom style, style mum or mom, fashion mom, fashion mama, we found accounts which feature mum/mom, and/or fashion or style as part of their moniker - for example, @astylemum or @fashionmumof40. All feature motherhood and fashion as part of their 'feed.'

To capture a wider range of Instagrammers than just celebrities, our protocol sampled 24 UK and US mums using Launchmetrics' categorisation of four 'tiers' of 'influencers,' from 'celebrity' (over 1.5 million); 'mega' (between 501k-1.5million); 'macro' (between 101-500k); to 'micro' (between 10-100k). For the mums with under $10 \mathrm{~K}$ followers we 
added a fifth tier, 'nano' influencer, which allowed us to observe demographics and aesthetic sensibilities different from the mainstream. We chose Instagram because "recent industry reports suggest that $93 \%$ of influencer campaigns include Instagram, about twice as many as YouTube or Facebook," (Williams, 2018, as quoted in Omeara, 2019:3). Our sample is diverse in terms of age, race, body size (compared to 'normal' fashionable instagrammers): all are over 30, some are in their $40 \mathrm{~s}$, and 10 are nonwhite.

\section{Theoretical Framework}

We analyzed our data through several lenses. To track patterns of taste inside the industry which reproduce the (fashionable) habitus, we use Bourdieu's $(1984 ; 1993)$ field analysis, layered with practice theory, which enables analysis of how aesthetics are maintained through working practices and institutional structures (i.e., histories of sizing and modelling norms) (Volonte, 2019). The emerging literature on 'platformatization' (Gillespie 2010; 2017; Duffy et al., 2019) is utilized to see how "platform" enables providers to appear neutral and apolitical, hiding the fallibly human labour shaping the algorithm behind the scenes.

\section{Findings}

The very juxtaposition of 'mum' or 'mom' with 'fashionability' or 'style' implicitly challenges ideals within fashion through an ongoing 'identity performance' (Rocamora 2011:411) foregrounding the complex and contradictory articulation between 'motherhood' and 'fashion.' Pushing the limits of fashion ideals, self-termed "style mums" often showcase older, curvier bodies, transformed by motherhood. For example, @motherofdaughters Clemmie Hopper noted, "When I tell people I'm a mum of 4 their usual reaction is 'you don't look like a mum and you don't dress like one either!' What does a mum even look and dress like? ....Motherhood shouldn't define you..." (11 December 2017). Similarly, @mothering.it states, "I feel so nervous about posting this bikini snap; I'm 5 months postpartum with my fourth child and this holiday I was no way "bikini ready"' (4 May 2019).

Style mums also articulate motherhood through style by narrating their identities as mums through techniques of 'mum style.' These 'techniques' offer commentaries on motherhood not afforded in fashion media, giving voice to mums traditionally not seen in fashion editorials (older, larger, black, or indeed all three). Mixed race UK mum Natalie @stylemesunday clearly challenges the fashion and beauty industries, through seeking to 'normalise cellulite and stretch marks, different body types and different abilities.' These 'techniques' of mum style engage in practices anathema to fashion - highlighting bargain shopping, a mum 'uniform', and unpolished images of their daily lives: 'Standard mum uniform today. These Mom jeans are SO comfortable! They're from good old @primark' (@thriftyyorkshiremum 11 February 2019). Many or our mums pose against the backdrop of ordinary domestic life, kitchens with messy work surfaces, or bedrooms with washing in the background. Throughout, we found a careful balancing act between projecting a quasi-glamourous life and 'authentic' depictions of motherhood. 
While the fashionable ideal was both challenged and reproduced through photographic conventions and practices specific to 'mum style,' notions of 'authenticity' competed with the pull towards commercialization, similar to findings in the social media literature. The paradoxical nature of 'mum' and style, however, positioned our respondents in ways that allowed for clear provocations to the fashion's 'homogenizing logic,' which merit further research.

\section{References:}

Abidin, C. 2016 'Visibility labour: Engaging with Influencers' fashion brands and \#OOTD advertorial campaigns on Instagram" Media International Australia, 161(1), 86-100.

Bourdieu, P. (1984) Distinction, New Jersey: Routledge.

Duffy, B.E. (2017) (Not) Getting Paid to Do What You Love. New Haven: Yale University Press.

Duffy, B. E., \& Hund, E. (2015). "Having it all” on social media: Entrepreneurial femininity and self-branding among fashion bloggers.' Social Media + Society, 1(2), 111.

Duffy, B.E., et al. (2019) "Platform Practices in the Cultural Industries," Social Media + Society, Oct-Dec: 1-8.

Eikhof, D.R., Carter, S., and Summers, J. (2013) “"Women doing their own thing”" International Journal of Entrepreneurship, 19(5), 547 - 564.

Ekinsmyth, C. (2014) 'Mothers' business, work/life and the politics of "mumpreneurship."' Gender, Place \& Culture, 21(10), 1230-1248.

Ekinsmyth, C. (2013) Managing the business of everyday life: the roles of space and place in 'mumpreneurship'. International Journal of Entrepreneurial Behaviour, 19(5).

Findlay, R. and de Perthuis, K. (2019) "How Fashion Travels: The Fashionable Ideal in the Age of Instagram," Fashion Theory, 23(2), 1-24.

Gillespie, T. (2010). The politics of 'platforms.' New Media \& Society, 12(3), 347-364.

Gillespie, T. (2017) "The platform metaphor, revisited"

http://culturedigitally.org/2017/08/platform-metaphor/ [accessed 2/18/20].

Marwick, A.E. (2013). Status Update. New Haven: Yale University Press.

Omeara, V. (2019) 'Weapons of the Chic,' Social Media + Society, Oct-Dec. 2019: 111.

Orgad, S. (2019) Heading Home, New York: Columbia University Press. 
Rocamora, A. (2011) “Personal Fashion Blogs," Fashion Theory, 15(4), 407-24.

Senft, T. (2008). Camgirls. New York: Peter Lang.

Volonté, P. (2019). 'The thin ideal and the practice of fashion.' Journal of Consumer Culture, 19(2), 252-270.

Williams, R. (2018) 'Study: 93\% of influencer campaigns use Instagram.' Mobile Marketer. Retrieved from www.mobilemarketer.com/news/study-93-of-influencercampaigns-use-instagram, 2/20/20. 


\title{
ED-FLUENCERS: SUBJECTIVITIES OF LEARNING AND LABOR IN SOCIAL MEDIA TRAINING PROGRAMS
}

\author{
Agnès Rocamora \\ London College of Fashion \\ Brooke Erin Duffy \\ Cornell University \\ Arturo Arriagada \\ Universidad Adolfo Ibáñez
}

\section{Introduction}

In early 2020, Jake Paul-the buzzy American YouTuber known for his frat boy antics and patently offensive humor-announced the launch of the "Financial Freedom Movement," a \$19.99/month educational platform targeting social media star wannabes (Leskin, 2020). Paul's pitch to young digital aspirants, namely that they could learn to be "financially free from the 'societal cookie cutter life' 9-5 jobs we are all told to have," invoked the well-worn narrative of entrepreneurial meritocracy-one that, crucially, elides the patterned inequalities that structure success in the social media and technology industries '(Marwick, 2013; Noble and Roberts, 2019). Perhaps not surprisingly, analysts dismissed Paul's pseudo-instructional initiative as a scam; it was, after all, not the first time Paul tried to make inroads into content creator training (Leskin, 2020). Others, meanwhile, called attention to Paul's unabashedly antieducation tack (Yap, 2020). Such critiques notwithstanding, we contend that such "edfluencer" programs (the name of Paul's initial training course) index a confluence of factors in social media, education, and employability that deserves further critical attention.

Indeed, a staggering number of influencer/creator training initiatives have been launched in recent years, ranging in scope from creator-run programs like Paul's to international franchises like Social Star Creator Camp to annual conferences like Ignite Influencer Marketing Bootcamp and VidCon. Similarly, higher education institutions across the world have started offering potential graduates courses on various aspects of digital marketing. The curricula have a kaleidoscopic range of course offerings: "Influencer Marketing," "Image Consulting," "E-commerce," "Fashion Trends," and "Algorithms and Analytics," among others. The popularity of these programs can be understood against the backdrop of wider popular culture's tendency to fetishize social media careers (Duffy \& Wissinger, 2017) as well as persistent debates about the marketisation of higher education.

Together, these orchestrated activities work as resources through which forms of knowledge and expertise are commercialized and exchanged in order to create reputation across digital platforms. At the same time, institutionalized forms of knowledge and expertise around careers, creative expression, and celebrity produce 
subjectivities of learning and labor. More broadly, these ideals participate in the production and reproduction of the figure of the ideal worker of neoliberalism.

Whilst much attention has been paid to labour (including digital labour) in the creative industries, the issue of the ways labour is shaped and defined by education has been somewhat overlooked. The present paper attends to this gap in the literature on creative industries and digital labour by examining the cultural, economic, and political dimensions of influencer educational programs.

Given the cultural embeddedness of educational debates in particular geographic contexts as well as the global-local nexus of influencer labor, we focus on three social media educational markets: the United Kingdom, Chile, and the U.S.

We do this by analyzing a group of institutions that sell influencer marketing courses, asking questions such as: how do different countries embrace influencer marketing and the skills required to achieve it? What are the ideological contexts that configure this industry of knowledge? Who do these programs say about digital labour and the role and values of education in the formation of future workers? By deploying a critical lens, we are especially attentive to questions about idealized worker subjectivities in terms of gender, race, class, age, and ethnicity.

\section{Methodology}

Our in-progress study draws upon a qualitative textual analysis of course websites promoting influencer/creator education programs across Chile, the United Kingdom, and the U.S. We analyzed 9 courses per country, using a strategically selected distribution of 3 university courses, 3 private (non)-university courses, and 3 online courses $(n=27)$. We identified those courses combining online research, using keywords like "social media courses," "influencer courses," "digital marketing courses," and "social media and content creation" for each country. The unit of analysis was the content of each course's website, including but not limited to its general description, the content of each course, and the expected results and benefits communicated to prospective students. The qualitative coding schema was guided by the preliminary observation of the data where different categories of analysis emerged. We used a grounded theory approach by combining data collection and analysis (Glasser \& Strauss 1967) in order to refine the concepts and categorical themes presented in the analysis. We supplement this with data from in-depth interviews with both aspiring influencers and influencer marketing managers.

\section{Summary of Findings}

Thus far, our analysis of data has yielded the following preliminary themes:

1) Technology--specifically social media platforms-- and the values and/or meanings given to technical skills versus knowledge of the cultural and aesthetics of particular sites.

2) Knowledge, or the way each course frames the value of learning and then encourages the application. Often, the courses encouraged a sort of continued upkeep 
of platform knowledge while reaffirming the value of less evergreen ideals (i.e., creating "valuable content.")

3) Labour, or what kind of work is represented by a content creator, and the abilities required to do it properly. While some courses cast courses as a way to learn "competences for the production and management of digital communication projects," others emphasized less tangible modes of work (such as building relationship).

4) Expertise, or what kind of values and meanings are attributed to being qualified or certified on a set of abilities by an institution. Here we pay particular attention to the types of laboring subjectivies who get cast as "experts," particularly those that reproduce inequalities (Bishop, 2020).

By exploring these themes in particular cultural-geographic configurations, we address how influencer labour is defined and represented as well as the kind of self that is imagined and promoted in educational discourses.

\section{References}

Bishop, S. (2020). Algorithmic experts: Selling algorithmic lore on Youtube. Social Media+ Society, 6(1), 2056305119897323.

Cunningham, S. and Craig, D. (2019). Social Media Entertainment: The New Intersection of Hollywood and Silicon Valley. New York: New York University Press.

Duffy, B. E., \& Wissinger, E. (2017). Mythologies of creative work in the social media age: Fun, free, and "just being me". International Journal of Communication, 11, 20, 111.

Glaser, B., \& Strauss, A. (1967). The discovery of grounded theory: Strategies for qualitative research.

Marwick, A. E. (2013). Status update: Celebrity, publicity, and branding in the social media age. New Haven, CT: Yale University Press.

Noble, S., \& Roberts, S. (2019). Technological Elites, the Meritocracy, and Postracial Myths in Silicon Valley.

Leskin, (2020, February). P. YouTuber Jake Paul is trying to cash in on teaching fans how to become influencers - two years after his first project failed. Business Insider. Retrieved from: https://www.businessinsider.com/jake-paul-financial-freedommovement-influencer-school-edfluence-team-1000-2020-2

Yap, A. C. (2020, February 15). YouTuber Jake Paul Launches Entrepreneur How-To Platform, Financial Freedom Movement. Variety. Retrieved from:

https://variety.com/2020/digital/news/youtube-jake-paul-launches-financial-freedommovement-1203505286/ 


\title{
ARE YOU ADVERTISER AND FAMILY FRIENDLY? PRODUCTIVE AMBIVALENCE, ECONOMIES OF VISIBILITY AND THE POLITICAL POTENTIAL OF FEMINIST YOUTUBERS
}

\author{
Zoë Glatt \\ London School of Economics and Political Science \\ Sarah Banet-Weiser \\ London School of Economics and Political Science

\section{Introduction}

Of all the social media platforms that have garnered attention in the past decade for the promises of widespread access for ordinary individuals, perhaps none has achieved the kind of visibility as YouTube. As the second most popular website in the world, preceded only by its parent company Google, YouTube has accumulated over 1.9 billion logged-in users each month, 500 hours of content uploaded every minute, and over 1 billion hours of content watched daily (YouTube 2019). Here, entrepreneurial content creators are harnessing the platform to build their own brands within the emerging social media entertainment industry, or SME (Cunningham and Craig 2019). Feminist content is a well-established genre on YouTube, in which creators post political and social commentary on topics such as intersectionality, politics, gender and sexual identity alongside comedic, lifestyle, and personality-driven fare.

While looking to advance feminist cultural agendas, these creators are situated within an economy of visibility (Banet-Weiser 2018), incentivized to adopt certain norms and trends if they wish to garner likes, views and subscribers. These creators exist within the cultural context of popular feminism. Popular feminism is part of a larger context of what Catherine Rottenberg has called "neoliberal feminism," where corporate- and media-friendly feminist expressions achieve a heightened visibility, and expressions that critique patriarchal structure and systems of racism and violence are often obscured (Banet-Weiser 2018; Bishop 2018; Rottenberg, 2014; McRobbie, 2009). In other words, many of these creators both advance and profit from popular feminism: brand-safe feminist discourses that dovetail comfortably with neoliberal agendas. Seeing and hearing a safely affirmative feminism, in spectacularly visible ways often eclipses a feminist critique of structure; the visibility of popular feminism on YouTube is important but it often stops there, as visibility. That said, the platform has also provided a cultural space for more marginal groups and radical left-wing politics to flourish; the visibility of diverse, LGBTQ and gender-fluid identities on YouTube far outstrips its broadcast media counterparts.

In this paper, we aim to complicate the dominance of popular feminism online by asking: to what extent are professional YouTube content creators able to present more radical versions of feminism, or else pushed to fit into neoliberal brand culture in order to gain visibility and income? As with every development of a new technology, a utopic/dystopic discourse frames YouTube's creation and reception and, we argue, as many have about emerging media technologies, this framing does not help push us forward to a 
more nuanced analysis of the cultural impact of YouTube. Here, we attempt such a nuanced analysis by positioning feminist YouTube content within what Burgess and Green (2018) have called a 'cultural system', one that both provides openings and foreclosures for specific kinds of cultural and political participation. Specifically, we theoretically frame our analysis within the popular feminist economies of visibility and, following feminist theorists Clare Hemmings and Lauren Berlant, an interrelated theoretical analytic of productive ambivalence, to analyse content creators in a cultural, economic and social context of popular feminism. We see this kind of political ambivalence in a battle with what Banet-Weiser has called an economy of visibility. Economies of visibility describe the ways in which visibility of particular identities and politics, such as gender, race and sexuality, circulate on multiple media platforms. While this visibility is important for public awareness, it also potentially becomes an end in itself, where "visibility is all there is" (Banet-Weiser, 2018).

\section{Methodology}

As an offshoot of a broader 4-year ethnographic project looking at the lived experiences and labour of YouTube content creators, we identified 40 prominent feminist content creators, ranging from 'brand-safe' and heteronormative on the one hand to more queer and radical on the other. We then carried out content analysis of their videos as well as participant observation of these creators across platforms (including YouTube, Twitter, Instagram and Patreon), paying attention to their cultural positionality, content style/topics, income streams and modes of address to their audiences.

\section{Findings}

While recognizing that there are blurred boundaries between political ambivalence and economies of visibility, we nonetheless analyse feminist YouTubers within this typology, finding that while there are some similar messages across different feminist YouTube channels, there are also those that are seeking increased recognition and visibility within a capitalist framework, and some who are better characterized as politically ambivalent, more complex and contradictory. Only certain feminist expressions and politics on YouTube easily merge with market logics, whilst other more marginal identities face additional obstacles. Nowhere is this marginalization made clearer than in the ongoing struggles that LGBTQ+ YouTube creators have had with their content being demonetised and age restricted due to not being "advertiser and family friendly". We tease out the tensions, identifications and disidentifications within the analytics of political ambivalence and economies of visibility by investigating some popular contemporary feminist creators on YouTube (Ash Hardell Melanie Murphy, ContraPoints and Kat Blaque) as they navigate two intersecting approaches to feminist content creation: 1) transactional: working within a popular feminist economy of visibility concurrent with capitalist logics, and 2) transformational: the ambivalent process of attaining visibility within YouTube's attention economy as a route to radical social change.

The work of feminist content creators on YouTube is complex and we resist a reductive explanatory frame here. Our point in analysing these videos as transactional or transformational is not to say that there are defined borders that separate these two 
aspirations, but rather to say that it makes more sense to think about the feminist politics of YouTube creators within a framework of political ambivalence. YouTube has been celebrated by many as a platform that has enabled far more diverse screen representations of race, gender and sexuality than television and film media, as is undoubtedly the case. However, feminist YouTube creators have to navigate what are often contradictory pressures in order to gain visibility and earn a living, such as appealing to commercial brands whilst simultaneously maintaining authenticity and relatability with their audiences. Rather than insist that feminist content creators are either enabling or inhibiting feminist politics, or rather than insist on the certainty of feminist politics on YouTube, we follow Hemmings in her resistance to the notion that such politics can be completely "knowable."

\section{References}

Banet-Weiser, S. (2018). Empowered: Popular Feminism and Popular Misogyny. Durham, USA: Duke University Press.

Bishop, S. (2018). 'Anxiety, panic and self-optimisation: Inequalities and the YouTube algorithm'. Convergence: The International Journal of Research into New Media Technologies. 24:1, pp. 69-84.

Burgess, J. and Green, J. (2018). YouTube: Online video and participatory culture. Cambridge, UK: Polity Press.

Cunningham, S. and Craig, D. (2019). Social Media Entertainment: The New Intersection of Hollywood and Silicon Valley. New York: New York University Press.

Hemmings, C. (2018). Considering Emma Goldman: Feminist political ambivalence and the imaginative archive. London, UK: Duke University Press.

McRobbie, A. (2016). Be creative: making a living in the new culture industries. Cambridge, UK: Polity.

Rottenberg, C. (2018). The Rise of Neoliberal Feminism. New York, USA: Oxford University Press.

YouTube. (2019). 'YouTube for Press' [online]. YouTube website, 13th August. Retrieved from: https://www.youtube.com/int//en-GB/yt/about/press/ 